\title{
Cervical erector spinae plane block catheter for shoulder disarticulation surgery
}

\author{
Hassan Hamadnalla, MD · Hesham Elsharkawy, MD, MBA, MSc, FASA · Tetsuya Shimada, MD • \\ Kamal Maheshwari, MD, MPH • Wael Ali Sakr Esa, MD, PhD • Ban C. H. Tsui, MD, MSc $\mathbb{1}$
}

Received: 12 May 2019/Revised: 25 May 2019/Accepted: 27 May 2019/Published online: 3 June 2019

(C) Canadian Anesthesiologists' Society 2019

\section{To the Editor,}

For shoulder disarticulation surgery, a continuous brachial plexus (BP) block is suboptimal because of close proximity to the surgical field and inadequate anesthetic coverage for thoracic dermatomes. Recently, a novel description was published outlining the use of a T2-3 erector spinae plane (ESP) catheter advanced into a cervical location from the thoracic level to serve as an alternative to a BP block for complex upper extremity procedures. ${ }^{1}$ Instead of facing potential challenges from threading an ESP catheter from the thoracic region, we report (with patient consent) a similar case of a patient undergoing a unilateral shoulder disarticulation but with an ESP catheterization at the C7 level.

H. Hamadnalla, MD

Department of Outcomes Research, Anesthesiology Institute, Cleveland Clinic, Cleveland, $\mathrm{OH}$, USA

H. Elsharkawy, MD, MBA, MSc, FASA - K. Maheshwari, MD, $\mathrm{MPH} \cdot$ W. A. S. Esa, MD, PhD

Department of Outcomes Research, Anesthesiology Institute, Cleveland Clinic, Cleveland, OH, USA

Department of General Anesthesiology, Anesthesiology Institute, Cleveland Clinic, Cleveland, OH, USA

T. Shimada, MD

Department of Outcomes Research, Anesthesiology Institute, Cleveland Clinic, Cleveland, $\mathrm{OH}$, USA

Department of Anesthesiology, National Defense Medical College, Saitama, Japan

B. C. H. Tsui, MD, MSc $(\square)$

Department of Anesthesiology, Stanford University, Stanford, CA, USA

e-mail: bantsui@stanford.edu
A 62-yr-old, 82-kg male with left lower lobe stage IV lung carcinoma presented with intractable pain due to a pathologic fracture of the left distal humerus. His baseline analgesics included methadone $15 \mathrm{mg}$ and gabapentin 60 mg every $12 \mathrm{hr}$, with additional oxycodone 10-20 mg every three hours when needed. Preoperatively, with the patient in a right lateral position, a 17G Tuohy needle was inserted under ultrasound guidance (Figure A) through the trapezius, levator scapulae, and deep cervical muscles (i.e., erector spinae muscles) until it contacted the left posterior tubercle of the $\mathrm{C} 7$ transverse process (TP). After negative aspiration, $10 \mathrm{~mL}$ ropivacaine $0.5 \%$ was injected with visualization of its spread between the deep cervical muscles and the middle and posterior scalene muscles posterior to the C7 TP. A $19 \mathrm{G}$ catheter was then threaded 3 $\mathrm{cm}$ beyond the needle tip and another $5 \mathrm{~mL}$ of ropivacaine $0.5 \%$ was injected through the catheter with a similar spread pattern observed. The ESP catheter was tunneled and secured to the right side of the neck (Figure B). His preoperative sensory examination revealed a loss of cold sensation with ice in the $\mathrm{C} 4$ to $\mathrm{T} 4$ dermatomes. After disarticulation involving the glenohumeral and scapulothoracic joints, the postoperative infusion rate was set at $6 \mathrm{~mL} \cdot \mathrm{hr}^{-1}$ of ropivacaine $0.2 \%$ with a demand bolus of $6 \mathrm{~mL}$ every hour. The only opioid the patient received intraoperatively was $50 \mu \mathrm{g}$ fentanyl. Postoperatively, the patient received oral acetaminophen $1 \mathrm{~g}$ every eight hours along with his pre-op gabapentin $600 \mathrm{mg}$ and methadone $15 \mathrm{mg}$ every $12 \mathrm{hr}$. Other opioid requirements were 10 and $20 \mathrm{mg}$ of oxycodone during postoperative day (POD) 0 and 1 , respectively. At rest, his weighted average numeric pain rating score over $48 \mathrm{hr}$ was 2 of 10 (range, 0-5). He continued to have a demonstrable loss of cold sensation from $\mathrm{C} 4$ to $\mathrm{T} 2$ around the shoulder stump and chest wall area on POD 1 and POD 2. The catheter was removed, and 


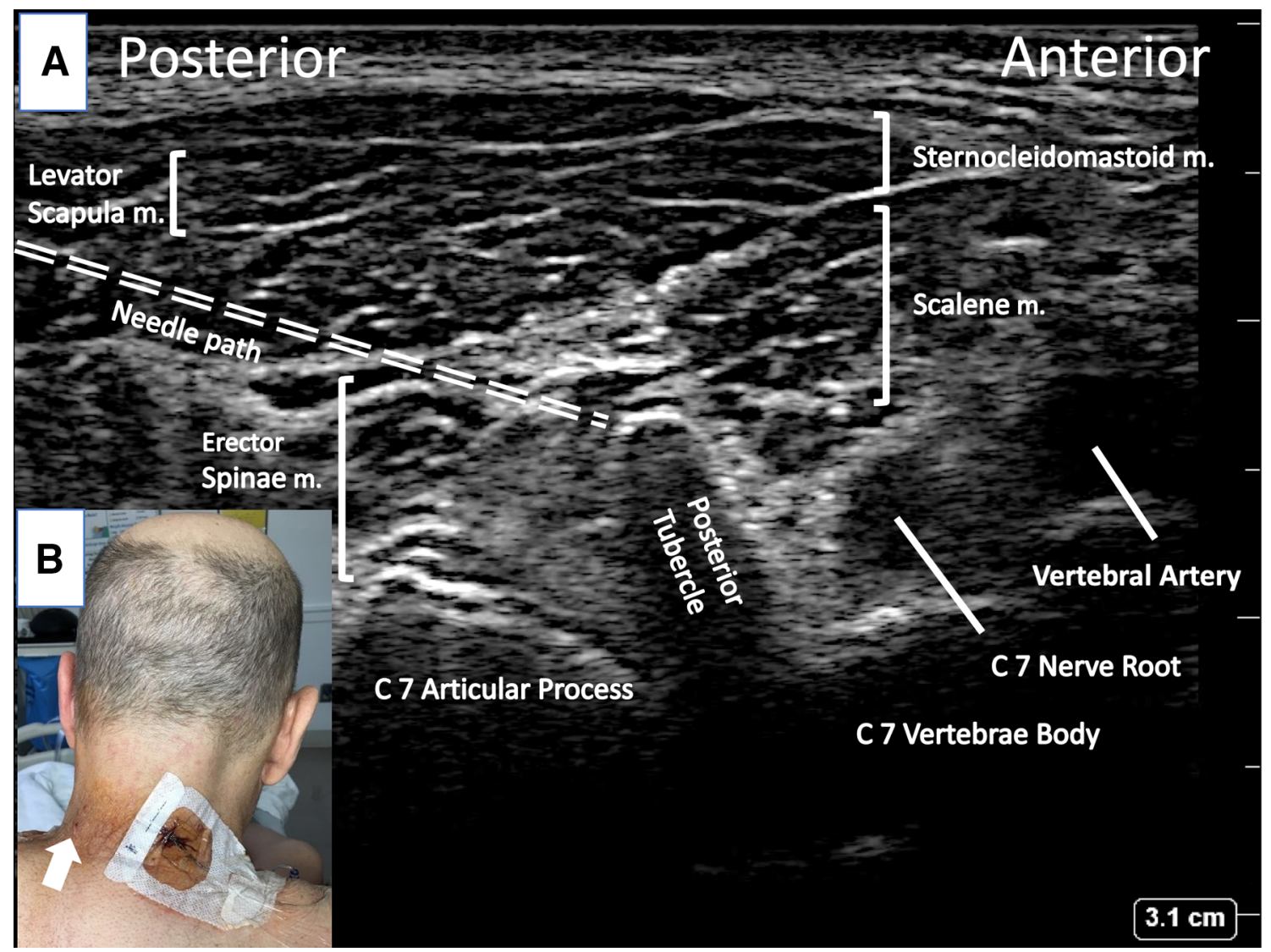

Figure Continuous erector spinae plane catheterization. A) Transverse ultrasonographic posterior view with a linear array transducer (12-15 mHz, X-Porte, SonoSite, Bothell, MA, USA) shows the in-plane needle insertion path with the transit through the layers of the trapezius, levator scapulae, and erector spinae muscles (m.) until it contacts the tip of the cervical $\mathrm{C} 7$ transverse process that was identified by its narrow tip and absence of anterior tubercle. B) Erector spinae plane tunneled catheter (Flexblock, FB-19609-K, Teleflex, Morrisville, NC, USA). After infiltration of the skin with

the patient was discharged on POD 2. No hemidiaphragmatic paresis was detected using ultrasound.

This report suggests that a C7 ESP block can provide effective analgesia for a patient undergoing shoulder disarticulation. Postoperative analgesia can be accomplished as needed from adequate cranial-caudal local anesthetics spread to cover the target sensory level from $\mathrm{C} 4$ to $\mathrm{T} 4{ }^{1,2}$ These observations are consistent with previous imaging studies that the direct injection of $20 \mathrm{~mL}$ of local anesthetic via an ESP block at the T2 level can spread up to C3 level. ${ }^{2,3}$ The approach used here is similar to the commonly described continuous cervical paravertebral block using a posterior approach. ${ }^{4}$ Instead of the needle being "walked off" the bony cervical TP to reach the BP, the needle (and catheter) remain posterior to the cervical TP. Despite this, we postulate that the local anesthetic of ESP enters the interscalene groove and upper lidocaine $2 \%$ on the right side of the neck about $5 \mathrm{~cm}$ from the original catheter entry point (white arrow), the same 17G Tuohy needle was passed from this point toward the entry point of the catheter. With continuous palpation, the needle was advanced within the subcutaneous tissue plane deep enough to avoid the dermis but sufficiently superficial to avoid injury to any deep structure. The catheter was then tunneled via the Tuohy needle to the right side of the neck and fixed in place with a sterile dressing

thoracic paravertebral space providing BP and intercostal coverage. Importantly, although the catheter being further away from the phrenic nerve and the bony TP may guard the vertebral artery, there is still a theoretical risk of phrenic nerve paresis and vertebral artery injury.

\section{Conflicts of interest None declared.}

Editorial responsibility This submission was handled by Dr. Hilary P. Grocott, Editor-in-Chief, Canadian Journal of Anesthesia.

\section{References}

1. Tsui BC, Mohler D, Caruso TJ, Horn JL. Cervical erector spinae plane block catheter using a thoracic approach: an alternative to brachial plexus blockade for forequarter amputation. Can J Anesth 2019; 66: 119-20. 
2. Forero M, Rajarathinam M, Adhikary SD, Chin KJ. Erector spinae plane block for the management of chronic shoulder pain: a case report. Can J Anesth 2018; 65: 288-93.

3. Ohgoshi Y, Terada S, Usui Y, Matsuno K. Analgesia-related differences among the erector spinae, multifidus cervicis, and inter-semispinal plane blocks. Can J Anesth 2018; 65: 958-60.

4. Borene SC, Rosenquist RW, Koorn R, Haider N, Boezaart AP. An indication for continuous cervical paravertebral block (posterior approach to the interscalene space). Anesth Analg 2003; 97: 898900.

Publisher's Note Springer Nature remains neutral with regard to jurisdictional claims in published maps and institutional affiliations. 